\title{
Comparison of Growth Morphology in Ge (001) Homoepitaxy Using Pulsed Laser Deposition and MBE
}

\section{Citation}

Leonard, John P., Byungha Shin, James W. McCamy, and Michael J. Aziz. Comparison of growth morphology in Ge (001) homoepitaxy using pulsed laser deposition and MBE. Materials Research Society Symposium Proceedings 749: W16.11.

\section{Published Version}

http://www.mrs.org/s_mrs/sec_subscribe.asp?CID=2572\&DID=118884\&action=detail

\section{Permanent link}

http://nrs.harvard.edu/urn-3:HUL.InstRepos:2797691

\section{Terms of Use}

This article was downloaded from Harvard University's DASH repository, and is made available under the terms and conditions applicable to Other Posted Material, as set forth at http:// nrs.harvard.edu/urn-3:HUL.InstRepos:dash.current.terms-of-use\#LAA

\section{Share Your Story}

The Harvard community has made this article openly available.

Please share how this access benefits you. Submit a story.

\section{Accessibility}




\section{Comparison of Growth Morphology in Ge (001) Homoepitaxy Using Pulsed Laser Deposition and MBE}

John P. Leonard, Byungha Shin, James W. McCamy, Michael J. Aziz

Division of Engineering and Applied Sciences, Harvard University, Cambridge, MA 02138.

\section{ABSTRACT}

Differences in the homoepitaxy of $\mathrm{Ge}(001)$ are explored using a dual MBE/PLD deposition system. With identical substrate preparation, temperature calibration, background pressure and analysis, the system provides a unique comparison of the processes arising only from kinetic differences in the flux and at the surface. All films show mounded growth. At substrate temperatures below $200^{\circ} \mathrm{C}$, PLD films are smoother than MBE films, whereas they are similar at higher temperatures.

\section{INTRODUCTION}

Molecular beam epitaxy (MBE) and pulsed laser deposition (PLD) are generally viewed as techniques capable of producing high-quality epitaxial films. Although both processes typically involve vapor phase deposition of a monomer flux onto a substrate, there are important differences associated with the generation and characteristics of the beam. In traditional MBE the beam is produced by thermal evaporation of a liquid or solid source, yielding a steady state flux with low energy — typically $1 \mathrm{eV}$ or less. In PLD a pulsed laser beam is focused onto a target from which, through complex interactions involving melting and plasma formation, a plume of material is ejected. Under typical conditions, the plume contains a partially ionized population of monomers, with a broad distribution of energy ranging from ten to a few hundred $\mathrm{eV}$, as shown in Figure 1b. Deposition of material on a substrate placed in or near this plume occurs in microsecond pulses of high instantaneous flux, often orders of magnitude higher than with steady-state MBE.

(a)

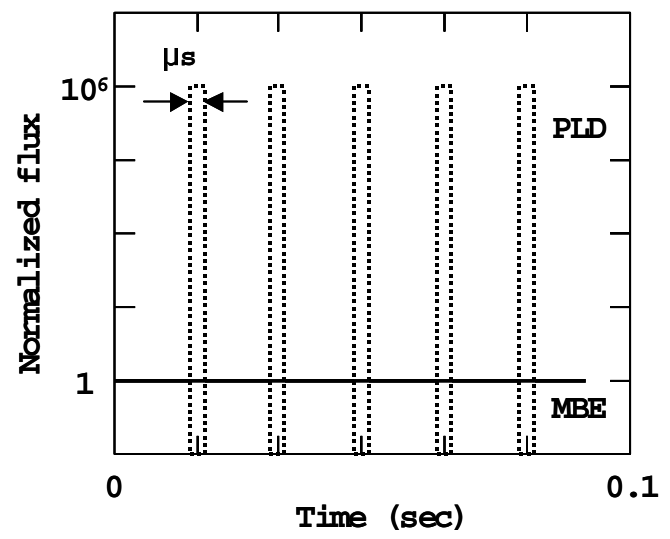

(b)
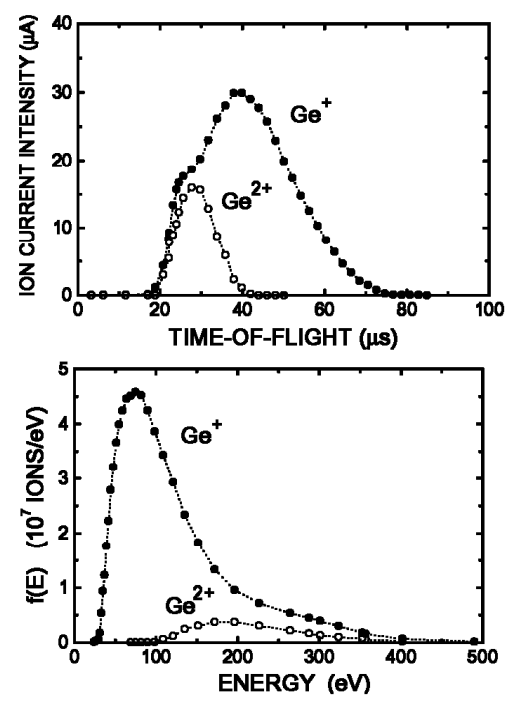

Figure 1. a) Schematic comparison of deposition rates in PLD and MBE. b) Typical characteristics of flux in PLD of germanium, adapted from Franghiadakis et al. [1]. 
Significant experimental and theoretical work over the last few decades has provided a good understanding of steady-state MBE growth. Successful kinetic models involve the interplay of the competing diffusional processes for roughening and smoothening. In the case of PLD, the additional complexities of a broad energy distribution and transient effects associated with the pulsed flux have limited the current understanding. Several 'enhanced' MBE techniques have recently been developed which suggest that an energetic and pulsed flux can have important effects on epitaxy: 1) Interrupted (or pulsed) MBE which uses a modulation of the flux to control the supersaturation of monomers on a surface, thereby changing island nucleation rates to produce smoother films [2]. 2) Ion-assisted MBE that incorporates low-energy (30-100 eV) ion bombardment during deposition to affect island nucleation, impurity pinning, vacancy generation and subsurface recoil implantation [3]. 3) Ultrahigh vacuum (UHV) sputtering to produce an energetic flux $(10-150 \mathrm{eV})$ that leads to increased surface mobility, subsurface implantation, and penetration of hydrogenated surfaces [4-6].

The open question that our current study seeks to answer is whether PLD, with its energetic pulsed flux, can also produce improved epitaxial films. Recently, kinetic Monte Carlo (KMC) simulations have been conducted that suggest that a lower roughness for PLD at low temperatures [7-9]. As shown in Figure 2, at low temperatures the simulations found that an energetic flux produced smoother films, presumably due to the effects of enhanced surface diffusivity of adatoms in the first 5 ps after arrival as well as surface cluster erosion by incident atoms. At high temperatures these effects are less important due to higher intrinsic surface mobility, yielding similar results for MBE and PLD. Additional rate equation models for pulsed and energetic flux are also being developed [10], which suggest additional effects relating to instantaneous flux and frequency dependence of pulses.

Figure 2. Simulation results from Taylor et al.[8] showing surface height standard deviation for 10 monolayers of homoepitaxial $\mathrm{Si}(001)$ deposited at various temperatures. Solid lines correspond to MBE and PLD, while upper and lower dashed lines are for pulsed thermal and steadystate energetic flux respectively.

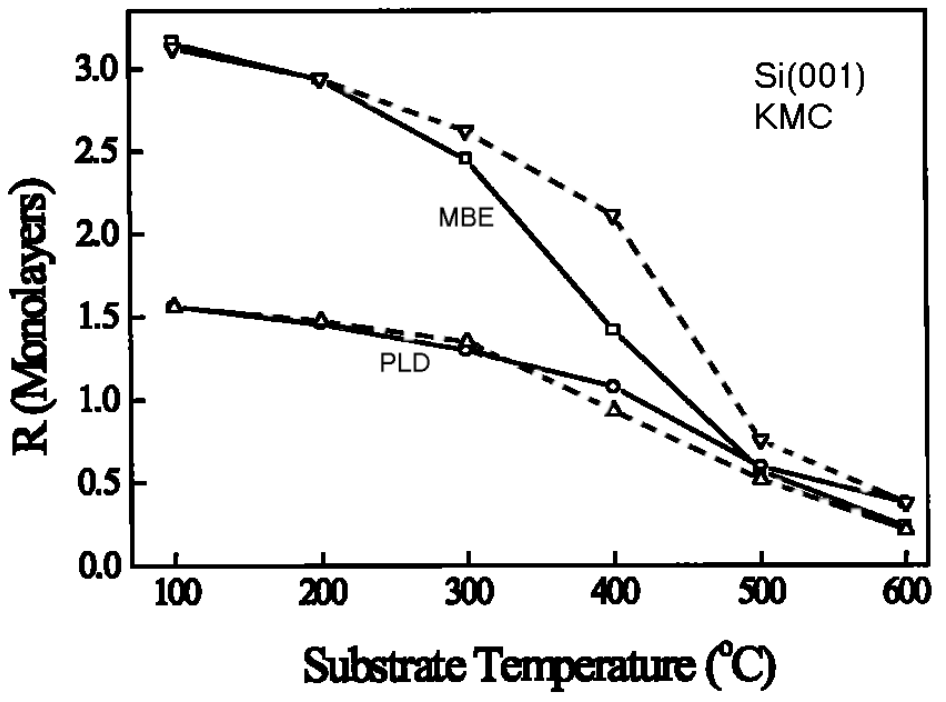

Experimental studies $[5,11]$ of epitaxy via PLD typically demonstrate smoother films, a lower kinetic roughening temperature, and increased critical epitaxial thickness. However these are typically not under ultrahigh-vacuum (UHV) conditions, and compared only to MBE results in the literature (i.e. different chambers). It is commonly known that with MBE, the background pressure, starting surface, and temperature calibration are critical to epitaxy results $[5,12]$ and 
comparisons must ensure that these are identical. Until now, detailed experimental comparisons of MBE and PLD under identical conditions have not been conducted.

\section{Germanium (001) homoepitaxy}

Germanium (001) homoepitaxy is selected as the model system because of its increasing use in group IV semiconductor technology, and because there is extensive literature on surface preparation and growth of Ge [13-18]. Extensive MBE investigations of this system show a rich morphology as summarized below. At low temperatures, layer-by-layer growth is initially found, but subsequent growth results in the formation of a mounded morphology followed by a transition to amorphous growth at the lowest temperatures. Both phenomena are believed to arise from kinetic roughening processes, and remain the subject of continued study for both $\mathrm{Si}$ and Ge [19-21]. In our experiments, a substate temperature of 90 to $200^{\circ} \mathrm{C}$ and film thickness of $50 \mathrm{~nm}$ is chosen to provide a well-developed mound structure that can be readily analyzed and compared in films deposited via MBE and PLD.

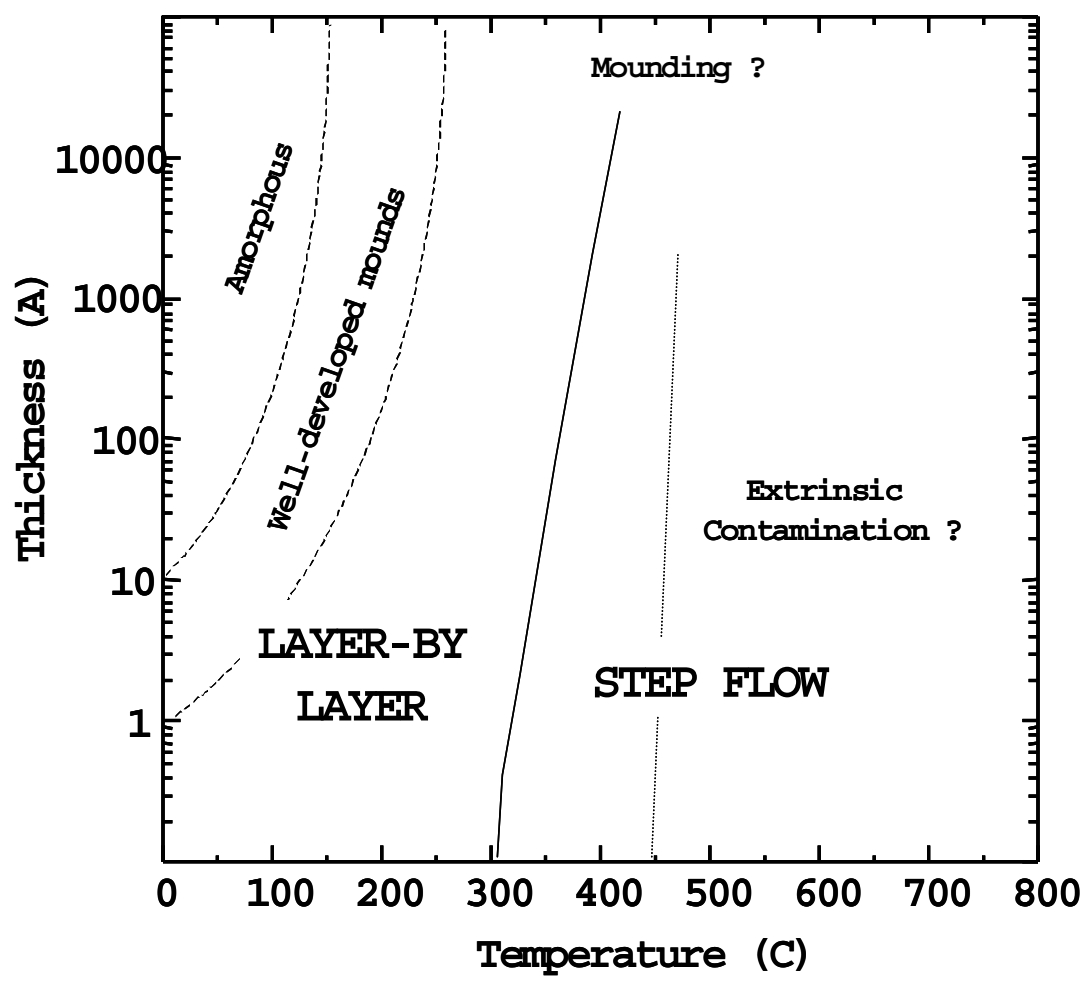

Figure 3. Temperaturemorphology map for Ge (001) homoepitaxy collected from existing Ge (001) MBE literature. In the low-temperature regime, a multilayer mounded morphology evolves with increasing film thickness, followed by a transition to amorphous growth.

\section{EXPERIMENT}

The same chamber is used for all deposition. It consists of standard equipment associated with MBE, including load-locking, UHV with a base pressure of $7 \times 10^{11}$ Torr, 5 -axis sample manipulator, backside tungsten filament heating as well as water-cooled stage. Molecular beam epitaxy is provided by solid source effusion cell, while a quartz window and laser ablation rotating-target system are added to provide pulsed-laser deposition capabilities. Pulsed laser deposition is obtained using a KrF laser (248nm, $22 \mathrm{~ns} \mathrm{FWHM,} 20 \mathrm{~Hz}$ ), quartz window and rotating target manipulator, with target-to-substrate distance of $2 \mathrm{~cm}$ or larger. 
Substrates are low-miscut $\left(<0.5^{\circ}\right.$, Eagle Picher) Ge (001), cleaved to approximately $1 \times 2 \mathrm{~cm}$ pieces which, after cleaning, are attached to a molybdenum platen with indium and load-locked into the chamber. Sample surface temperatures can be held between 20 and $800^{\circ} \mathrm{C}$, and monitored with a type-C thermocouple attached to the platen face, as well as with a low temperature infrared pyrometer for temperatures above $400^{\circ} \mathrm{C}$. In-situ analysis is via RHEED to monitor crystal quality flatness, and deposition rate calibration is via ex-situ film thickness measurements and RHEED oscillations. Surface morphology is immediately analyzed ex-situ with tapping-mode AFM in air. Although some oxidation is expected upon removal, little change in film morphology is found for extended periods of air exposure.

a)

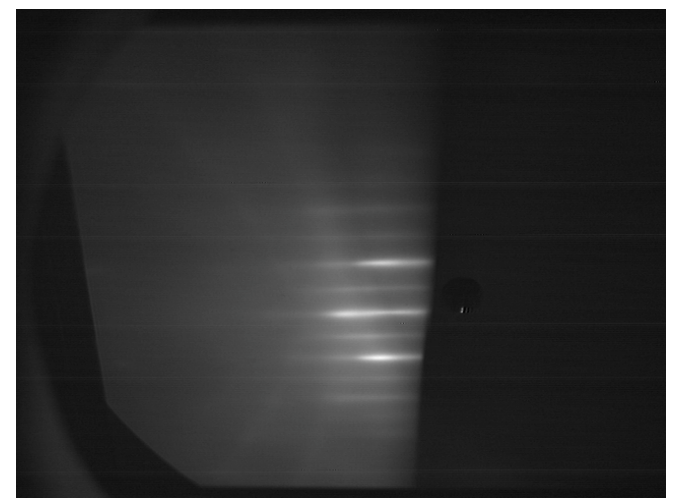

b)

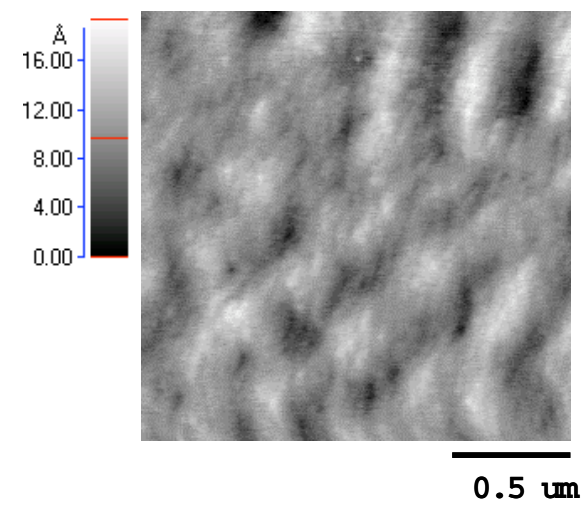

Figure 4. (a) RHEED image of Ge(001) surface after buffer layer deposition and flash anneal, 15 $\mathrm{kV},<110>$ azimuth, $\theta=1.5^{\circ}$, (b) AFM tapping-mode image of same (after removal from chamber) showing smooth surface with calculated RMS roughness below $1 \mathrm{~nm}$.

Surface preparation is based on the methods of Zhang et al. [15], consisting of repeated cycles of ozone-assisted oxidation, followed by in-situ desorption of oxide in the chamber. A $40 \mathrm{~nm}$ buffer layer is grown at the 'magic' temperature of $380^{\circ} \mathrm{C}$, followed by a $500^{\circ} \mathrm{C}$ flash anneal [16]. This procedure provides a smooth, vicinal starting surface free from carbon and other contamination that would otherwise act as pinning sites for step motion [17].

\section{RESULTS}

Films of $50 \mathrm{~nm}$ were grown homoepitaxially at $0.014 \mathrm{~nm} / \mathrm{sec}$ via MBE and PLD at various temperatures, using identical sample preparation and chamber conditions. All films show a mounded morphology qualitatively consistent with other MBE studies of Ge (001) homoepitaxy [16]. Films deposited by PLD are consistently smoother for low temperatures, while similar roughness is obtained via $\mathrm{MBE}$ and $\mathrm{PLD}$ at $200^{\circ} \mathrm{C}$. Power spectral density analysis (radially averaged) shows a characteristic lateral spacing of 250 to $300 \mathrm{~nm}$ associated with the mounds in all cases. 


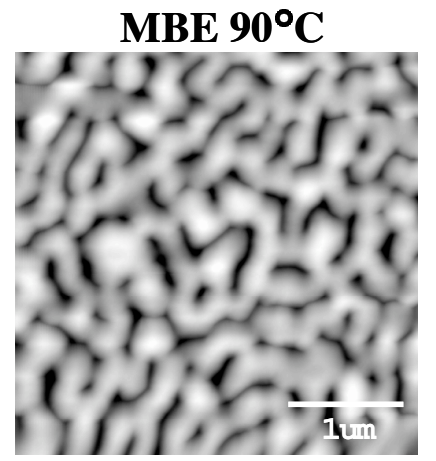

$\mathrm{h}_{\mathrm{rms}}=129 \AA \mathrm{h}_{\mathrm{pv}}=709 \AA$

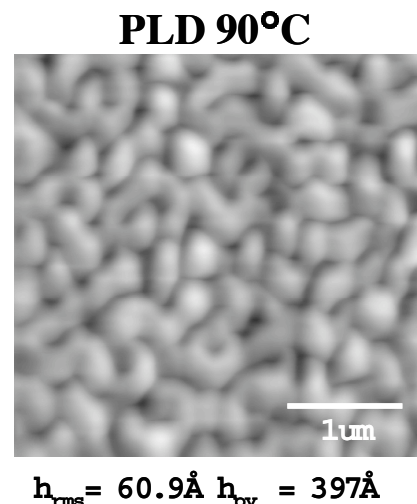

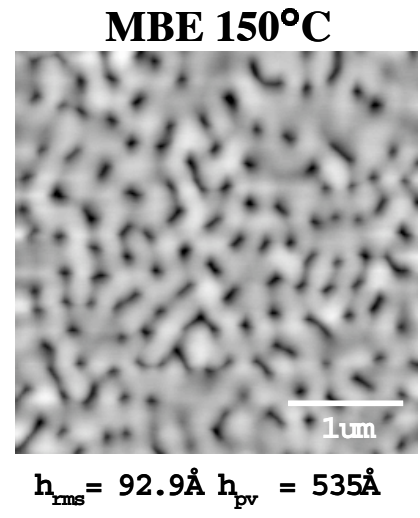

PLD $150^{\circ} \mathrm{C}$

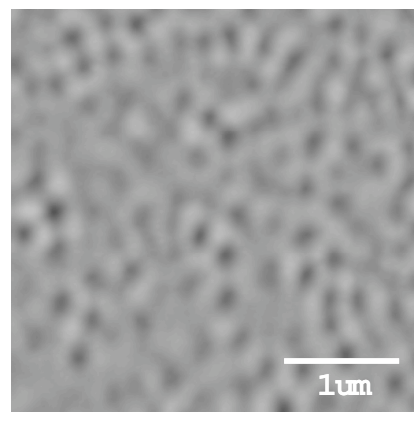

$h_{\mathrm{rms}}=28.2 \AA \mathrm{h}_{\mathrm{pv}}=277 \AA$
MBE $200^{\circ} \mathrm{C}$

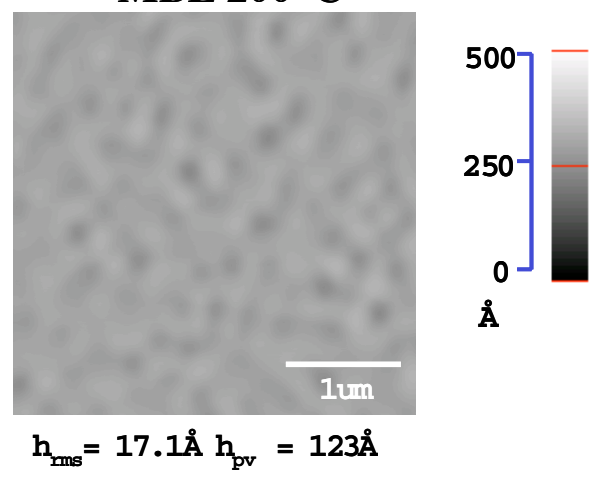

PLD $200^{\circ} \mathrm{C}$

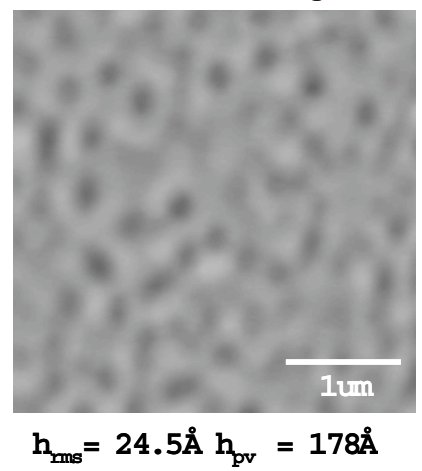

Figure 5. AFM images of PLD and MBE films at various temperatures, taken from random 4 x 4 um regions in the center of each sample, plotted at identical grayscale range.

Figure 6. Summary of RMS roughness values obtained from films in Figure 5. Buffer layer roughness is shown at $380^{\circ} \mathrm{C}$ for comparison.

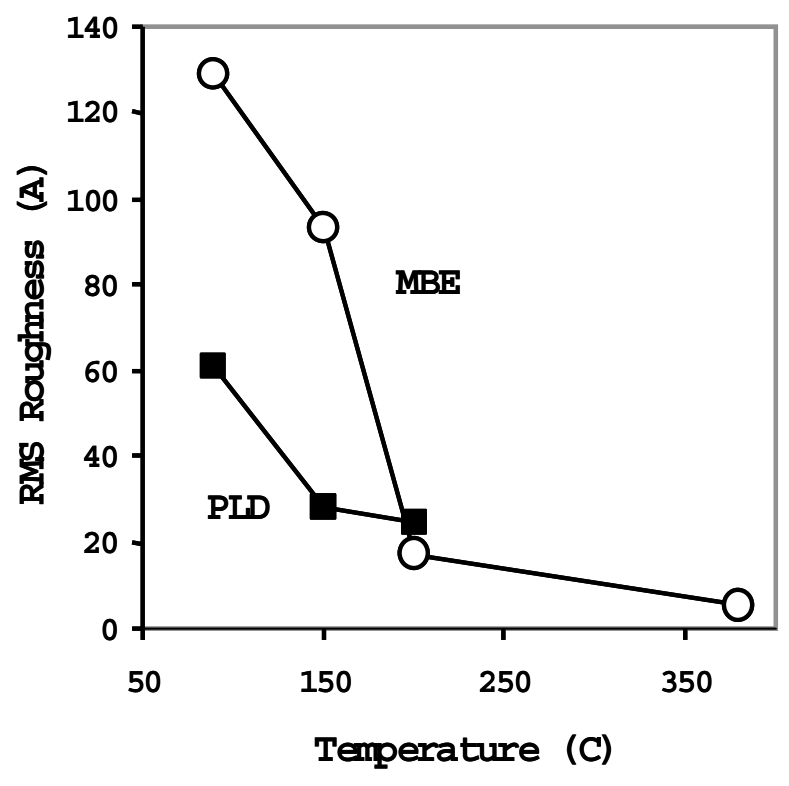

\section{DISCUSSION}

These experiments are unique in that MBE and PLD processes have been compared under identical conditions, eliminating effects due to differences in sample preparation, temperature 
calibration, and vacuum conditions. We find PLD produces high-quality Ge(001) homoepitaxial films that are similar to MBE at high temperatures, but are significantly smoother at low temperatures. This qualitatively supports the KMC results of Taylor et al. [7-9] for the analogous $\mathrm{Si}(001)$ homoepitaxial system (see Figure 2). While confirmation at a variety of film thicknesses is needed, this work is an important step toward testing their assertion that energetic effects play a dominant role in determining roughness evolution in these systems. The advantages of PLD, particularly in independent adjustments of mean flux, instantaneous flux, pulse rate, pulse width, and energy distribution, make it well suited to address such fundamental kinetic processes associated with epitaxy.

\section{ACKNOWLEDGEMENTS}

The authors also wish to thank David Cahill and Arvind Raviswaran for helpful discussions and assistance in obtaining clean Ge surfaces. This research was supported by NSF grant DMR97-27369.

\section{REFERENCES}

1. Y. Franghiadakis, C. Fotakis, P. Tzanetakis, Appl. Phys. A 68, pp. 391 (1999).

2. V.A. Markov, O.P. Pchelyakov, L.V. Sokolov, S.I. Stenin, S. Stoyanov, Surf. Sci. 250, 229 (1991)

3. E. Chason, J.Y. Tsao, K.M. Horn, S.T. Picraux, H.A. Atwater, J. Vac. Sci. Technol. A 8, 2507 (1990).

4. J.E. Greene, N.E. Lee, Nucl. Instr. Meth. B 121, 58 (1997).

5. M.V.R. Murty, H.A. Atwater, Surf. Sci. 374, 283 (1997).

6. J.W. Rabalais, A.H. Al-Bayati, K.J. Boyd, D. Marton, J. Kulik, Z. Zhang, W.K. Chu, Phys. Rev. B 53, 10781 (1996).

7. M.E. Taylor, H.A. Atwater, M.V.R. Murty, Thin Solid Films 324, 85 (1998).

8. M.E. Taylor, H.A. Atwater, Appl. Surf. Sci. 127-129, 159 (1998).

9. S.G. Mayr, M. Moske, K. Samwer, M.E. Taylor, H.A. Atwater, Appl. Phys. Lett. 75, 4091 (1999).

10. N. Combe, P. Jensen, Phys. Rev. B 57, 15553 (1998)

11. H. Jenniches, M. Klaua, H. Hoche, J. Kirschner, Appl. Phys. Lett. 69, 3339 (1996).

12. D.J. Eaglesham, J. Appl. Phys. 77, 3597 (1995).

13. J. Aarts, A.J. Hoeven, P.K. Larsen, J. Vac. Sci. Technol. A 6, 607 (1988).

14. M.H. Xie, J. Zhang, S.M. Mokler, J. Fernandez, B.A. Joyce, Surf. Sci., 320, 259 (1994).

15. X.J. Zhang, G. Xue, A. Agarwal, R. Tsu, M.A. Hasan, J.E. Greene, A. Rockett, J. Vac. Sci. Technol. A 11, 2553 (1993)

16. J.E. Van Nostrand, S.J. Chey, M.A. Hasan, D.G. Cahill, J.E. Greene, Phys. Rev. Lett. 74, 1127 (1995).

17. L.H. Chan, E.I. Altman, Y. Liang, J. Vac. Sci. Technol. A 19, 976 (2001).

18. C.L. Berrie, S.R. Leone, J. Cryst. Growth 216, 159 (2000).

19. C. Schelling, G. Springholz, F. Schaffler, Thin Solid Films 369, 1 (2000).

20. J.E. Van Nostrand, S.J. Chey, D.G. Cahill, J. Vac. Sci. Technol. B 13, 1816 (1995).

21. N.E. Lee, D.G. Cahill, J.E. Greene, Phys. Rev. B 53, 7876 (1996). 